Elsevier

RSM 00053

\title{
Hippocrates
}

\section{AIDS treatment and patient pressures}

For the desperate, understandably, progress in medicine is never fast enough. The American Clinical Pharmacologist Mark Reidenberg is one of those who has raised a warning finger at the ease with which new potential drugs in the struggle against AIDS have been made available by the Food and Drug Administration. Certainly, it is an approach which many an agency has long adopted with respect to new remedies for cancer; however feeble a promise of progress they may bear, no one is anxious to withhold them from the practitioner or his patients. There comes a point, however, at which caution may be thrown all too readily to the winds. Whosoever scans Scrip, the pharmaceutical industry's bright yellow chronicle, can only sense the misunderstanding which is arising; the relaxing of regulatory requirements has come to be viewed merely as the sweeping aside of another piece of useless bureaucracy; that agencies like the FDA are there to protect the public (and very often succeed in doing so, when they are allowed) seems to be an old-fashioned idea.

As Danner has very recently recalled, in a superb little review in The Netherlands [1] even the rapidity of therapeutic progress in the AIDS field to date - only four years elapsed between the identification of the pathogen and the marketing of the first clinically active anti-HIV drug - will readily be regarded by those who have contracted the infection as too slow. AIDS patients have developed a well-organized, assertive and eloquent campaign to open the therapeutic floodgates. It was primarily the pressure of the patient movement which led to the acceptance in the U.S. of zidovudine after the completion of a single multi-centre trial which showed an effect over a period of barely six months and which documented an impressive spectrum of adverse effects. Dideoxy-inosine (DDI) was made available to American physicians without reasonable proof of its efficacy and almost simultaneously with the commencement of Phase I and Phase II studies. What then happened was that less than a hundred patients proved willing to participate in a controlled study, whereas many thousands received the drug without adequate control. There are some authoritative arguments to the effect that this was not the right way to proceed.

In the meantime, the pressures on the individual physician and institute have mounted in a similar manner. Some bodies have ridden with the punch, in the hope of at least exposing useless claims for what they are (or are not) worth. Such was the approach to Extract Q, obtained from the roots of the Chinese cucumber and shown to have an anti-HIV potency in vitro; thanks to the San Francisco General Hospital compound Q was properly studied, and proved to be both useless and dangerous. Such studies, however, have not impeded the growth of an alternative circuit of unrecognized AIDS remedies, reminiscent of that (Laetrile!) which has existed for many years in the field of cancer. The same process is now under way with Kemron, a very questionable oral product which contains a low dose of interferon-alpha, and the reputation of which appears to have derived from poorly documented work in Africa, publicised only in the lay media.

In the face of policy dilemmas and patient pressures it seems hardly likely that the flow of contenders will be dammed up until the day when a serious and well-studied AIDS remedy emerges. What is evident is that the physician who goes along with the uncontrolled use of an 
unproven remedy is serving neither his patients nor the community well. Where unproven agents enter the market, with or without official blessing, one can only properly justify their use under conditions where their wanted and unwanted effects can be properly documented. As Danner puts it: "Treatment with unregistered drugs other than in the framework of systematic study is often termed 'compassionate use', thereby suggesting that clinical study is not concerned with compassion and sympathy. The reverse is the case. Once physicians cease to believe that good patient care and good clinical investigation can and must co-incide, the quality of both will soon suffer." Eloquent, and true.

1 Danner SA. AIDS, interventiestudies and patiëntendruk Ned Tijdschr Geneeskd 1990;134:1835-1836. 